\title{
Data Philanthropy: An Explorative Study
}

\author{
Jordana George \\ Baylor University \\ Jordana_George@baylor.edu
}

\author{
Jie (Kevin) Yan \\ Dalton State College \\ jyan@daltonstate.edu
}

\author{
Dorothy Leidner \\ Baylor University and Lund University \\ Dorothy_Leidner@baylor.edu
}

\begin{abstract}
Data philanthropy, which is firm donations of data, data scientists, and data technologies for social good, is a powerful new phenomenon that offers benefits to both donor firms and society. In this explorative research we unpack data philanthropy, providing definitions, and examples along with a theoretical perspective from corporate philanthropy and strategic management. We view data through a lens from the resource-based view of the firm. Based on the premise that data is an asset of the firm, we discuss how data philanthropy conforms and differs from traditional corporate philanthropy. Given data's requirements for substantial complementary assets and appropriate context, we propose that data can be shared for social good without harming the firm and may result in unforeseen benefits for the firm. In analyzing three examples, we offer several propositions regarding this new phenomenon.
\end{abstract}

\section{Introduction}

The data economy ushered in by the 21 st century has disrupted organizations and markets across the globe, forever changing how we look at business, government, and social welfare. Brought about by the vast increase of data creation and availability, the data economy refers to organizational leverage of data as assets, information, control, governance, and even as a means of exchange and revenue, such as that seen in the data-rich technology giants Facebook, Amazon, and Google [8]. Organizations worldwide are beginning to look towards their own data exploitation but meet with varying levels of success depending upon their IT intensiveness and industry competitiveness [27]. This results in big wins for some and failed efforts for others. This is because using data in general is a multi-sided challenge to be overcome: 1) it requires high quality data in appropriate quantities to be meaningful; 2) it requires skilled data workers such as analysts and data scientists to clean, massage, query, analyze, summarize, and visualize the data into actionable information; 3 ) it requires context so that meanings are not distorted (the context may include competitive environment, industry, customer base, profit margins and workforce); and 4) it requires substantial technology in the forms of computing power, storage, and specialized software and tools. If one piece of the puzzle is missing or reduced, data

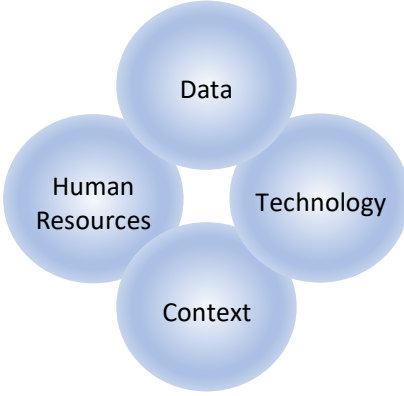

Figure 1. Elements of Data Utilization exploitation may be compromised [8, 27]. These elements are depicted in Figure 1. Yet for-profit organizations are not the only players in the data economy. Nonprofits, governments, especially digital government [16], and non-governmental organizations (NGOs)

have taken up the data promise as well, in hopes of building economies, reducing social inequalities, and improving the environment [14]. In a new twist on traditional corporate philanthropy, nonprofits are asking for corporate help, but rather than cash or inkind gifts, they want data philanthropy. "Data philanthropy is a modern extension of traditional corporate philanthropic activities," suggested Mallory Soldner Freeman, a UPS data scientist promoting data philanthropy in corporate circles [43].

Data philanthropy is a new, but important topic for IS researchers and practitioners. Data, its formats, usage, and analysis, is a major field of research in IS [1]. Data is core to information systems and should reflect all aspects of the decision sciences, methods, and applications of data. Data philanthropy is part of the data economy and is an activity with great promise not only for organizations, but also for improving social welfare [24]. This paper contributes to the decision sciences, analytics, and data sciences literature with the following research questions: what is the impact of data philanthropy, and how can it be promulgated to benefit both donor firms and recipients? We introduce this new form of philanthropy, explore its precedents and background, offer a current picture through three examples, and 
discuss the implications for data donors and recipients. This introduction serves as a starting point for future research in data philanthropy.

The paper continues as follows: to provide a theoretical background, we review the extant literature on data philanthropy, corporate philanthropy, and the resource-based view of the firm. Next, we describe three examples to provide current illustrations of data philanthropy and further provide a discussion and propositions based on these instances and the extant literature. We conclude with a research agenda and a call for future investigation.

\section{Background}

\subsection{Data Philanthropy Related Literature}

Data philanthropy has recently received attention with the rise of corporate big data and analytics that provide a wealth of new capabilities [33, 34]. It is usually initiated by corporate donors who want to leverage their data capabilities to advance social good [32]. As noted earlier, firms can participate in data philanthropy by not only sharing their data but by providing data knowledge, expertise and tools. Firms can, for example, partner with governments and leverage the firm's in-house expertise to conduct analyses and release the findings for broader use. Firms can also work with their nonprofit partners to provide additional expertise and capacity (e.g., data scientists and data analysis tools) if the partners have good data but lack the personnel and technology to utilize the data effectively [29, 32]. Therefore, data philanthropy may involve one or more entities or participants including governments, academia, nonprofits, corporations and individuals. Data philanthropy can be a win-win situation for both the recipients and the donors. Non-profits and individuals can benefit from data philanthropy through access to resources, knowledge, capacities or opportunities. And donor firms can enhance their public profiles, attract higher quality talent for better innovation, and improve their business environment $[32,33]$.

Overall, data philanthropy enables recipients and donors to work together to create solutions to society's big challenges and create unprecedented possibilities for informing and transforming society. In this paper, we adapt the United Nations Global Pulse's [39] view of data philanthropy and refer to data philanthropy as firm activities that include the following: 1) sharing aggregated and derived datasets for analysis under non-disclosure agreements, 2) allowing researchers to

\footnotetext{
${ }^{1} \mathrm{CSR}$ is usually described as an internal organizational policy or a corporate ethic strategy $[15,25]$. Like corporate philanthropy, CSR may be adopted by businesses for strategic or ethical purposes.
}

analyze data within the firm's own network, 3) engaging in real-time data commons: data pooled and aggregated between multiple firms of the same industry to protect competitiveness, 4) mining data behind the firm's own firewalls and share indicators, and/or 5) gathering and contributing data science expertise and skills. Table 1 lists some leading data philanthropy participants worldwide.

Table 1. Data Donators

\begin{tabular}{|l|l|l|}
\hline Name & Products and Services & Country \\
\hline Aimia & $\begin{array}{l}\text { Marketing \& loyalty } \\
\text { analytics }\end{array}$ & Canada \\
\hline $\begin{array}{l}\text { Ambry } \\
\text { Genetics }\end{array}$ & $\begin{array}{l}\text { Advanced genomic } \\
\text { services }\end{array}$ & US \\
\hline Deviant Art & $\begin{array}{l}\text { Online artwork, } \\
\text { videography \& } \\
\text { photography community }\end{array}$ & US \\
\hline DMCii & Satellite imaging services & UK \\
\hline ecobee & Home automation & Canada \\
\hline StackExchange & Online Q\&A community & US \\
\hline GitHub & $\begin{array}{l}\text { Software's version } \\
\text { control \& source code } \\
\text { management }\end{array}$ & US \\
\hline Google & $\begin{array}{l}\text { Internet-related services } \\
\text { and products }\end{array}$ & US \\
\hline Reddit & $\begin{array}{l}\text { Online social news } \\
\text { aggregation, web content } \\
\text { rating, \& discussion } \\
\text { community }\end{array}$ & US \\
\hline Syngenta & Agrochemicals \& seeds & Switzerland \\
\hline Twitch & $\begin{array}{l}\text { Live streaming video } \\
\text { platform }\end{array}$ & US \\
\hline Twitter & $\begin{array}{l}\text { Online news \& social } \\
\text { networking service }\end{array}$ & US \\
\hline Zillow & $\begin{array}{l}\text { Online real estate } \\
\text { database }\end{array}$ & US \\
\hline
\end{tabular}

\subsection{Corporate Philanthropy}

The extant literature on corporate philanthropy focuses on gifts of money, items, services, or in-kind assistance [31], while broader views go beyond corporate giving to include the domain of corporate social responsibility (CSR) ${ }^{1}$. The efficacy of corporate philanthropy on firm performance remains uncertain because of conflicting research, likely due to the heterogeneity of firms, their contributions, and their recipients [28, 42]. While some scholars propose a direct relationship between corporate philanthropy and strategic advantage [6], others suggest such actions go against the profit-making objective of the firm [14]. Still others propose that there is an optimal amount of corporate philanthropy that benefits performance with

From a strategic perspective, the aim of CSR is to increase longterm profits and shareholder trust $[14,25]$. 
a U-shaped relationship [41]. Most of the extant research on corporate philanthropy utilizes more objective quantitative measures of firm performance, while relatively few philanthropy studies employ the broader view of organizational effectiveness, which takes into consideration the general social and economic benefits to a firm's location and workforce [28].

The primary research questions for any type of corporate philanthropy remain: does philanthropy truly benefit the firm and how? This question comes up time and again because philanthropy is the act of giving away an asset of the firm without an expectation of getting something in return, and this goes against the premise that firms act in their own self-interest. Yet different ways of viewing those assets may shed light on how much their loss may or may not hurt the firm, and what benefits the firm may receive by the act of giving assets away. This leads us to the resource-based view of the firm.

\section{Theoretical Foundations}

\subsection{Resource-Based View of the Firm}

Focusing on data resources as an important facet of modern organizational effectiveness, we use a lens of the resource-based view of the firm (RBV) to examine the role and qualities of organizational data. RBV continues to offer key perspectives in the strategic management literature and other organizational fields [23]. RBV balances out the external focus of older industrial organization concepts such as the structure-conduct-performance (SCP) paradigm, transaction cost economics, and Porter's Five Forces [23]. RBV highlights the firm resources that make firms heterogeneous and thus provide sustained organizational effectiveness [21].

In $\mathrm{RBV}$, strategic resources are tied to firm performance and are a main source of sustained organizational effectiveness [9]. To be of strategic value in $\mathrm{RBV}$, resources must be valuable, rare, inimitable, and non-substitutable, a concept known by its acronym VRIN [5]. Resources must be valuable, meaning they significantly add value to the firm, its operations, or its position in some way. Resources must be rare, meaning that the resource is unique and not ubiquitous or a commodity. While rarity might indicate a specific resource by itself, it may also describe a particular combination of resources within the firm. Resources must be difficult to imitate, such as a unique technology or how people leverage the technology to provide organizational effectiveness. Last, resources must not have substitutes, i.e., non- substitutable, that allow rivals to create alternative strategies to arrive at the same result.

An interesting aspect of RBV is that it doesn't focus on any particular type of resources. Resources may be human, or a process, or a unique combination of people, places, and things. A key aspect of resources is that they are dependent on context [4]. A half empty plastic water bottle is trash when it resides in an urban garbage bin but is a lifesaving asset when found in a desert by a lost hiker. Data, for example, exhibits wide variation in value depending on context. Looking at data exhaust as an illustration, it could be considered trash in some contexts [14]. Data exhaust is the voluminous quantity of data spewing from IoT, smart city devices, and other internet enabled artifacts. But in the appropriate context, data exhaust could provide traffic pattern trends or predict road repair schedules. In this case, one person's trash can indeed be another's treasure. Whether data is trash or treasure comes down to the context and if it is treated as a byproduct or a resource of the firm.

\subsection{Data as a Resource of the Firm}

Data is considered a resource of the firm [5, 19]. Data is a foundation of knowledge, which is not only a strategic resource, but is also the key outcome of organizational knowledge production [19]. Data is the raw material that is then refined with the addition of context into information and shared as knowledge [2]. Data is an unusual asset because it is non-rivalrous, meaning that it can be used without diminishment. In some cases, using data can even increase its value through greater analysis and manipulation [14].

Data fits easily into Barney's VRIN framework. Data such as customer profiles, usage trends, and operational efficiencies may be valuable because they provide a basis for organizational decision making [19]. Firm data is rare because it is often unique and proprietary to the firm and not available from other sources. For example, we would not know what top Google searches are trending if Google did not share that data [17] because only Google has possession of such data. Firm data by its nature may not be imitated. While rivals may be able to glean similar statistics from their own data sources and statistics, rivals do not have access to other firms' data repositories that possess these firms' unique, idiosyncratic qualities. Last, firm data is not substitutable. For example, industry data may not be a substitute for firm data because industry data may be at a level that is too high and general to be of use. Likewise, competitor data may be too heterogeneous and specific to serve as a substitute for a firm's own data. This brings us then to 
the topic of the complementary assets needed to reap value from data.

\subsection{Complementary Assets}

Complementary assets are those resources required to utilize an asset. For example, if we consider data as an asset, but one has no computer to access it, the asset has little value. Complementary assets range from generic and widely available or highly specific and unique [36]. There is likewise a direct relationship between complementary asset specificity and transaction costs [4]. When complementary assets are highly specific they are often difficult to acquire or duplicate. Additionally, providers need additional motivation because the asset may have little value in other applications. These factors increase the costs associated with highly specialized complementary assets because the structural arrangements surrounding a resource will impact profit and competitive advantage [10, 36]. If the organization can internalize highly specified complementary assets with vertical integration, this can provide a barrier to competition.

The complementary assets required to exploit data resources are manifold. These include data gathering, preparation, repositories, analysis, and developing data driven decision making skills [20, 30]. Data gathering requires both hardware and software and can range from simple counts such as electrical usage tracking to facial recognition or license plate readers [26]. Using data requires technology [20, 30], but that in itself is insufficient. Data holds little value without the work performed by data scientists. These rare and sought after human resources massage, query, code, analyze, and visualize the data to tease out significant trends and implications, ultimately giving value to raw data through its transformation into actionable information [7]. Managers must have the ability to understand and act upon data driven decisions, and financial markets note that stockholders reward firms for business analytics-based decisions [38], but not all managers possess these skills [11]. Because so many complementary, expensive, and rare assets are required to exploit data resource, it is particularly resistant to imitation based on the dynamic capabilities view, which highlights the defensive capabilities afforded by resource combinations [37].

\subsection{Synthesis of Data Philanthropy and the Literature}

In this section we provide a brief overview of the primary foundations for data philanthropy (traditional corporate philanthropy and RBV). We then compare and contrast traditional philanthropy with data philanthropy to identify similarities and differences.

The objective of traditional corporate philanthropy is to benefit society. The participants include donors such as for-profit organizations, although non-profits sometimes financially support other nonprofits for strategic reasons. Traditional corporate philanthropy encompasses cash gifts, inkind gifts, services, employee volunteerism, facility sharing. The benefits to the firm may provide assistance with promotions, advertising, and marketing and may also help create/change corporate identity. A major challenge of traditional corporate philanthropy is that there is relatively little empirical evidence of benefits to the firm.

The objective in RBV is to understand where a firm's value lies and thus build/retain competitive advantage. The participants in RBV are primarily forprofit firms, although the principles are applicable for nearly any organization. RBV encompasses assets of the firm, which may be physical, virtual, or people. Assets must be VRIN to be considered strategic. The benefits found in RBV explain how VRIN resources provide competitive strategic advantage to the firm. The major challenge in RBV is that maintaining VRIN is difficult in today's fast-moving business environment. Nevertheless, we suggest that data, if used as a resource conferring strategic value, fits easily into the VRIN framework, which is summarized in Table 2.

\section{Table 2. Data and VRIN}

\begin{tabular}{|l|l|}
\hline & Data \\
\hline Valuable & $\begin{array}{l}\text { Provides metrics, trends, and } \\
\text { history used for decision making }\end{array}$ \\
\hline Rare & $\begin{array}{l}\text { The data is produced within the } \\
\text { firm and is not available from } \\
\text { other sources }\end{array}$ \\
\hline Inimitable & $\begin{array}{l}\text { Rivals may be able to produce } \\
\text { data about their own firm, but } \\
\text { cannot imitate the proprietary data } \\
\text { from others }\end{array}$ \\
\hline Non-Substitutable & $\begin{array}{l}\text { There is no substitute for firm data } \\
\text { Industry data may be inapplicable } \\
\text { or incomplete } \\
\text { Data from other firms, due to their } \\
\text { uniqueness, may be useless }\end{array}$ \\
\hline
\end{tabular}

In data philanthropy, the firm donates data, people, and/or technology, whereas corporate philanthropy could be considered an umbrella term within which data philanthropy is a subtype. Data is a strategic VRIN resource of the firm, unlike the cash or in-kind gifts that are more common in corporate philanthropy. The donation of data scientists is similar 
to other corporate philanthropy employee volunteerism. However, in-demand data scientists are far more valuable than the typical employee volunteer and loss of data analyst work hours could hurt the firm. The donation of technology is similar to corporate philanthropies such as donation of computers, cloud services, and software. Data philanthropy may also require the exchange of information and knowledge (those other than data) among the partners.

Furthermore, in data philanthropy of privateprivate partnerships, the data and knowledge shared may be aimed at building competitive advantage for private firms or an industry cluster. In such case, interorganizational relationship may become a salient issue to be managed. Data philanthropy may also require platforms that are dedicated to the interoperation and collaboration based on big data. Such data requires substantial complementary assets to be utilized, which impacts its value in donations. If recipients lack the precise complementary assets of the donor firm, the data may be utilized by recipients for the greater good without jeopardizing the firm. However, without sufficient complementary assets, data gifts may be useless to recipients. Additionally, the lack of complementary assets may lead users to use decontextualized data in inappropriate ways. Thus, recipients need a minimum amount of complementary assets to use the data but not enough to rival that of the donor firm. Table 3 summarized some similarities and differences between traditional and data philanthropy.

Table 3. Similarities and Differences between Traditional and Data Philanthropy

\begin{tabular}{|l|l|l|}
\hline & $\begin{array}{l}\text { Traditional } \\
\text { Philanthropy }\end{array}$ & $\begin{array}{l}\text { Data } \\
\text { Philanthropy }\end{array}$ \\
\hline Gifts & Not VRIN & VRIN \\
\hline Volunteers & Any employee & Data specialists \\
\hline Technology & $\begin{array}{l}\text { Usually not } \\
\text { required }\end{array}$ & $\begin{array}{l}\text { Big data } \\
\text { analysis tools \& } \\
\text { platforms }\end{array}$ \\
\hline $\begin{array}{l}\text { Information } \\
\text { Sharing }\end{array}$ & $\begin{array}{l}\text { Data \& } \\
\text { knowledge - } \\
\text { small amounts }\end{array}$ & $\begin{array}{l}\text { Data \& } \\
\text { knowledge - } \\
\text { large amounts }\end{array}$ \\
\hline $\begin{array}{l}\text { Complementary } \\
\text { Assets }\end{array}$ & $\begin{array}{l}\text { Few } \\
\text { complementary } \\
\text { assets required }\end{array}$ & $\begin{array}{l}\text { An appropriate } \\
\text { combination of } \\
\text { complimentary } \\
\text { assets required }\end{array}$ \\
\hline
\end{tabular}

\section{Method and Examples}

\subsection{Data and Example Selection}

In this section we provide three examples that illustrate the breadth of data philanthropy: United Parcel Service (UPS), MasterCard, and the United Nations Global Pulse Data for Climate Action
Innovation Challenge. These instances were chosen because they provide different illustrations of how data philanthropy was provided, used, and the impact of the gifts, thus providing a broad view of how data philanthropy is enacted today. The data is secondary having been drawn from company and nonprofit websites, corporate annual reports, and information from newspaper and magazine articles. Although most case research draws from interview data, some case studies have been published that rely upon publicly available data [e.g., 12].

UPS is a promoter of data philanthropy and this project is noted on its corporate foundation website. It is also heavily promoted on both Ted and YouTube. MasterCard is also well known because of its publicity around the project and we selected it because of its focus on economic inequality combined with the potential for financial growth for the donor firms. MasterCard was also selected because of a specific focus on data by its philanthropy arm. The Innovation Challenge was selected because it demonstrated how many firms can come together with researchers and NGOs to achieve global results with very widespread implications.

\subsection{Example: UPS}

UPS has become known in data philanthropy circles as a strong proponent of the movement, thanks in large part to the work of UPS employee Dr. Mallory Soldner Freeman. In 2016, Soldner Freeman presented a TED Talk at UPS that introduced, explained, and promoted data philanthropy. This TED Talk garnered more than a million views as of 2018. In this presentation, Soldner Freeman provided what is now considered one of the best-known definitions of data philanthropy: the corporate donation of data, data scientists, and data technologies for the gathering and exploitation of data [40].

Among a number of philanthropic activities executed through its non-profit UPS Foundation, UPS donates logistics data expertise that aids in disaster relief and the delivery of aid worldwide. Expediting aid logistics has been demonstrated to save significant costs for moving aid shipments. Such savings typically result in increasing the number of aid recipients. One example is Soldner Freeman's donated time with the World Food Programme (WFP). The WFP logistics optimization team included members of Tilburg University and Northeastern University, the WFP, and UPS. Two examples are noted in a paper published by the team in 2016: Iraq and Yemen. The work in Iraq provided a savings of $17 \%$ on 500,000 monthly aid shipments, which permitted an additional 85,000 food deliveries. The work in Yemen used data to examine 
the contents of four million food aid baskets in terms of items, people served per basket, nutritional value, and cost. The monthly baskets were based on feeding a family of six. Using the team's algorithms and donated data, it was found that the current food basket contents could be altered to provide similar nutritional content at a lower cost, thus providing aid to an additional million recipient families.

\subsection{Example: MasterCard}

In 2013, MasterCard, a global financial services company, launched the Center for Inclusive Growth. The goal of the Center was "to support financial inclusion in the developing world" and data philanthropy was a cornerstone of this endeavor. "Data is an enormous asset," stated the Center's president, Shamina Singh [3]. The data philanthropy plan provided data grants to non-profits, governments, NGOs, and sometimes other companies, along with analysis and interpretation. Data projects cover both regional areas, such as the economic impact of redevelopment programs in the rust belt of Chicago, as well as country-specific programs as found in Singapore and Kenya [35].

We specifically look at the Jaza Duka project in Kenya, which is a lesser developed country (LDC) that possesses great economic potential in terms of its micro-businesses. Based on information captured from cashless payments, data is key in this project because MasterCard sees cashless payments as a growth area, and one that provides enormous information about how and where people spend money.

Cashless payments also provide insights about individual creditworthiness, which is critical for markets that do not use traditional credit assessment tools such as those found in western countries. "There's no FICO score in countries like Ethiopia," says Singh. These regions benefit from new creditworthiness assessments that help individuals start and grow businesses that can lift them out of poverty. MasterCard uses the data to proxy credit scores to enable giving credit in LDCs. Such data is also important for capturing more economic data than is currently viewed, thereby providing a broader perspective on a region's economy. Operating in over 200 countries, MasterCard holds a wealth of individual and aggregate financial data that has a tremendous potential for improving the economies of LDCs [3].

In the Kenyan Jaza Duka micro-entrepreneur program, small shop owners work with MasterCard, Kenya Commercial Bank (KCB), and Unilever, a global consumer goods supplier. In the local language,
Jaza Duka translates as "fill up your store" [35]. MasterCard uses electronic payments via smartphone (without a need for a physical card) to provide payments between customers and the store and the store and its vendors. Jaza Duka also provides databased credit facsimiles for Unilever and banks to assess customer credit, payments, and micro-loans for inventory purchases. This project is expected to result in 20,000 small shop owners building their business and inventory and ultimately providing greater economic benefits in the region.

Unilever and MasterCard hope to expand to other regions around the globe in the future [30]. This example differs from others because of the triad of donor participants and the multi-sided results that should provide corporate economic benefits while improving social welfare in LDCs. The donors include three partner companies; MasterCard, KBC, and Unilever. No other non-profits or NGOs are involved, which is somewhat unusual for large-scale philanthropic activity. The companies involved approached the project in terms of social welfare, however, there is significant economic benefit for the firms if the project succeeds. We suggest that because of its risky nature, the Kenya project was best put forward as a philanthropic venture, but it may be viewed as an interesting melded case of philanthropy and rational behavior.

\subsection{Example: United Nations Global Pulse Data for Climate Action Innovation Challenge}

United Nations (UN) Global Pulse is a big data initiative promoted by the UN Secretary General. "Its vision is a future in which big data is harnessed safely and responsibly as a public good. Its mission is to accelerate discovery, development and scaled adoption of big data innovation for sustainable development and humanitarian action" (www.unglobalpulse.org). One of the first projects from Global Pulse was the Data for Climate Action Innovation Challenge.

In this initiative, nine companies provided anonymized data to be analyzed by researchers in hopes of discovering climate change solutions. These companies included BBVA Data \& Analytics, a financial data analytics company; Crimson Hexagon, an enterprise social media analytics company; Earth Networks, a weather and lightning sensor network operator; Nielsen, a global measurement and analytics company; Orange, a global telecommunications provider; Planet, an earth-imaging satellite network operator; Plume Labs, an environmental data sciences company; Schneider Electric, a global specialist in 
energy management and automation; and Waze, a free, real-time community-based traffic and navigation app. The anonymized data remains open and free for public use on the Global Pulse website. In addition to the nine data providers, Western Digital provided cash and travel prizes for winners, Microsoft offered cloudcomputing support, and Tableau provided data tools. Last, strategic advisors were provided from Ars Technica, Ciesen, and Wired. Non-profit strategic assistance was offered by Skoll Global Threats Fund.

The 2017 challenge focused on climate mitigation, climate adaptation, and relationships between climate change and social welfare such as poverty reduction, reduced inequalities, and health/wellbeing, as put forth in the UN 2030 Agenda for Sustainable Development. Using data provided by the donor companies, selected researchers had four months to analyze and present their findings. Final results provided a grand prize winner ("Electromobility: Cleaning Mexico City's Air with Transformational Climate Policies Through Big Data Pattern Analysis in Traffic \& Social Mobility"), three thematic awards, two winners in data visualization, and seven honorable mentions (http://www.dataforclimateaction.org). The subsequent research was quite varied in topic, which ranged from agriculture to pollution to flooding. The climate challenge is interesting in that it was spearheaded by a global NGO, the United Nations, and specifically by the big data arm of the UN. It is also intriguing because of the vast number and variety of participants, including over a dozen for-profit companies and researchers from more traditional venues such as universities and national/global research institutions.

\section{Discussion and Propositions}

Below we compare the three examples in terms of reach, donation types, participants and partners, and explicit and implicit benefits to the donor firms. The reach of these examples varied considerably. UPS focused on regional areas that receive aid, such as conflict area in Iraq and Yemen. MasterCard approached it regionally as well, but from an economic and emerging markets perspective, as demonstrated in Kenya. The Data for Climate Action Innovation Challenge was an international endeavor. The donation types demonstrated a wide range, as well. UPS donated data and data scientists. MasterCard provided both data and data scientists, as well. The Innovation Challenge, however, received donations of data, data scientists, strategic advisors, and technology from its many partners.
In terms of participants and partners, our examples ranged from quite limited to quite broad. Our first instance, UPS, worked with limited partners, including the World Food Programme, and researchers from Tilburg University and Northeastern University. MasterCard also worked with limited partners and is unique in that its partners (KCB and Unilever) are both for-profit firms. The Innovation Challenge included the greatest number of participants, including a primary sponsor (Western Digital), technology partners (Microsoft and Tableau), nine data grant firms, and researchers from international for-profit and non-profit institutions.

Understanding the benefits to donors is important to the continuation and promotion of any philanthropy, and data philanthropy is no exception. We define explicit economic benefit as the project's ability to ultimately produce revenues or improve/develop markets. UPS and the Innovation Challenge demonstrated no obvious economic benefits, however, the MasterCard project offered clear economic benefits for all three partners. The project also provides the potential to leverage the model in other LDC markets, possibly adding billions of dollars in new global revenue.

The implicit benefits to the donors in all three examples was widespread, if inconsistently acknowledged. UPS gained additional logistics data, algorithms, and experiences from working in these high-risk regions. Such work also increased employee satisfaction \& retention, particularly for talented data scientists such as Soldner Freeman. The MasterCard project generated traditional philanthropic promotional value for its partners, but more importantly, it spawned the development of new measures of credit-worthiness and regional economics that could aid in market evaluation and development. These innovations could open many new markets and ultimately add billions of dollars of revenue to MasterCard's business. The Innovation Challenge certainly offered "feel-good" participation benefits for donor companies. However, the data donors likely learned something from the research that used their data, and those insights might be valuable for the firm. Microsoft and Tableau might have learned from how the researchers used their technologies and perhaps could use such knowledge to enhance their products. Western Digital, the promoter and provider of cash and travel prizes, likely gained little operational value from the endeavor, although it gained marketing value. Table 4 highlights some key similarities and differences between the three examples.

Table 4. Example Comparison 


\begin{tabular}{|c|c|c|c|}
\hline & UPS & MasterCard & $\begin{array}{l}\text { Innov. } \\
\text { Challenge }\end{array}$ \\
\hline Reach & Yemen, Iraq & Kenya & Global \\
\hline Data resource & Logistics data & $\begin{array}{l}\text { Purchase } \\
\text { data, } \\
\text { payment } \\
\text { histories }\end{array}$ & $\begin{array}{l}\text { Weather \& } \\
\text { traffic data, } \\
\text { satellite } \\
\text { images, } \\
\text { financial \& } \\
\text { social } \\
\text { media data }\end{array}$ \\
\hline $\begin{array}{l}\text { Complementary } \\
\text { assets }\end{array}$ & $\begin{array}{l}\text { Data } \\
\text { scientists, } \\
\text { tools for data } \\
\text { analysis, fast } \\
\text { Internet access }\end{array}$ & $\begin{array}{l}\text { Data } \\
\text { scientists, } \\
\text { tools for data } \\
\text { clean \& } \\
\text { analysis, fast } \\
\text { Internet } \\
\text { access }\end{array}$ & $\begin{array}{l}\text { Data } \\
\text { scientists, } \\
\text { strategic } \\
\text { advisors, } \\
\text { tools for } \\
\text { data clean } \\
\text { \& analysis, } \\
\text { fast Internet } \\
\text { access }\end{array}$ \\
\hline $\begin{array}{l}\text { Participants \& } \\
\text { partnership }\end{array}$ & $\begin{array}{l}\text { Limited } \\
\text { partner, WFP, } \\
\text { researchers }\end{array}$ & $\begin{array}{l}\text { MasterCard, } \\
\text { KCB, } \\
\text { Unilever }\end{array}$ & $\begin{array}{l}1 \text { primary } \\
\text { sponsor, } 2 \\
\text { technology } \\
\text { partners, } 9 \\
\text { data grant } \\
\text { firms, } \\
\text { multiple } \\
\text { researchers }\end{array}$ \\
\hline $\begin{array}{l}\text { Explicit donor } \\
\text { benefits }\end{array}$ & None & $\begin{array}{l}\text { Open new } \\
\text { markets, test } \\
\text { new business } \\
\text { model }\end{array}$ & None \\
\hline $\begin{array}{l}\text { Implicit donor } \\
\text { benefits }\end{array}$ & $\begin{array}{l}\text { Received new } \\
\text { data, } \\
\text { algorithms \& } \\
\text { experiences in } \\
\text { high risk } \\
\text { regions, } \\
\text { increased } \\
\text { employee } \\
\text { satisfaction \& } \\
\text { retention }\end{array}$ & $\begin{array}{l}\text { Promotional } \\
\text { value \& } \\
\text { development } \\
\text { of new credit } \\
\text { measures, } \\
\text { aid in market } \\
\text { evaluation \& } \\
\text { development }\end{array}$ & $\begin{array}{l}\text { Donors } \\
\text { learned } \\
\text { from the } \\
\text { research } \\
\text { that used } \\
\text { their data }\end{array}$ \\
\hline
\end{tabular}

Based on the examples, we suggest several propositions. One, data philanthropy can be beneficial for donor firms in several ways. First, data philanthropy may provide firms an opportunity to mitigate business risk and foster innovation. For example, UPS, by donating data, acquired new algorithms and experiences which could help the firm more easily predict interruptions in deliveries in those high-risk regions in the future. MasterCard also tested its new business model in Kenya, a country that is lesser developed, bringing great economic opportunities to both the company and the country. Second, data philanthropy may provide donor firms an advantage in acquiring and retaining talent, as illustrated in the UPS example. In addition, the InnovationChallenge illustration shows that a data philanthropy initiative can attract external researchers (e.g., data scientists) and enable them to accomplish more meaningful things and derive findings that can be later learned and utilized by the donor firm. Third, data philanthropy can provide firms a means to invest in their business environment. By sharing their data for the public good, Mastercard, for example, facilitated greater awareness of their new technology in the region, enlarging the market and customer base. Beneficial usage of the donated data, which helps build economies and reduce poverty, would also ultimately enhance the donor firm's organizational effectiveness [33, 34]. Overall, we suggest that while data can be a powerful source of competitive advantage in today's business environment, the value of data philanthropy for donor firms runs along a continuum from micro to macro. There are explicit benefits for the donor firm that are easily identified, such as learning new skills in partnership with the recipient organization, as well as larger, harder-tomeasure benefits such as a better workforce and brand awareness. Data philanthropy should improve the competitive business environment within which the firm operates and provide strategic benefits to the donor firm. We thus propose:

Pla: Donor firms receive explicit benefits from participating in data philanthropy.

We also note from the examples that MasterCard appeared to receive greater benefits than the other two. The MasterCard example differed in several respects from the others. First, it involved a small group of three for-profit participants and no NGOs or nonprofits were involved. Second, none of the data was made public, although results are planned to be publicized. This seems to suggest an inverse relationship between the number of donor participants in data philanthropy and the degree of benefit. There could be several reasons for this. Smaller groups working together have greater control and may be more agile. They may be able to spot opportunities and act upon them where larger groups may not have this flexibility or conflicting project objectives may prohibit it. The absence of nonprofit voices may also allow the donor firms in a small group to leverage projects for two-way benefits that help both the cause and the donor firms. Last, small groups such as the MasterCard project exhibit closed data, while the other two exhibited more open data. The Innovation Challenge example, with its many participants, exhibited the greatest openness by publicly posting the data sets and the resultant research papers. Tying these findings and concepts together, we propose:

$P 1 b$ : Donor firms overall receive greater benefits when they participate in data philanthropy projects with designated partners and fewer participants.

Two, while the benefits for any firm embracing data philanthropy are considerable, the extent to which firms can conduct data philanthropy may hinge on the degree of their control of the complementary assets of data. As discussed earlier, data philanthropy assets do 
not merely refer to data but include all the complementary assets that are mandatory to make use of the data. A firm may have a data warehouse but can only initiate limited data philanthropy (i.e., sharing data) without analysts to analyze the data and share the insights/indictors. Also, a lack of expertise and capacity (e.g., data scientists) prevents firms from partnering with external organizations that possess big data but lack the personnel and technology to clean, analyze and use the data effectively [32]. Indeed, we note that in all three examples, a combination of data and complementary assets were required for the projects to use the data. Some firms offered just data, such as the nine data providers in the InnovationChallenge, and other partners provided the analysis. In the UPS and MasterCard examples, the firms offered both data and data scientists. Therefore, it appears that data philanthropy requires both parts data and analysis assistance - to be useful to a cause, although one firm does not have to provide everything if other partners can be found.

In short, we suggest that firms that deploy successful complementary assets of data will not only receive greater value from their data but will be in a better position to participate in data philanthropy. This leads us to the following propositions:

P2a: Data philanthropy requires both data and complementary assets to be useful to the cause.

$P 2 b$ : The degree of control of complementary assets of data positively influences data philanthropy activity.

\section{Conclusion}

Data philanthropy is new, but we suggest it is a pivotal topic in IS research, and one with substantial benefits for practitioners. Data is uniquely an IS topic and we should embrace this opportunity to benefit both society and organizations. We asked the following questions: what is the impact of data philanthropy and how can it be promulgated to benefit both donor firms and recipients? We believe we have answered these inquiries with descriptions and reallife examples of data philanthropy across a wide range of circumstances. We suggest that data philanthropy is a burgeoning field and one that we hope will engender future research interest. To that end, we offer several suggestions to build the field. First, it would be interesting to examine how data philanthropy activities vary and the subsequent impact those activities have on the donor firms. Second, researchers might explore data science educational opportunities within data philanthropy, especially in terms of data science students working with donated data. This is important because there is a worldwide shortage of data scientists and analysts $[18,20]$. Last, the value of data philanthropy within e-government and policy making could reveal important insights that could impact millions. Whether used in a micro or macro setting, data philanthropy offers great promise, both for donors and recipients.

\section{References}

[1] R. Agarwal and V. Dhar, "Editorial—Big Data, Data Science, and Analytics: The Opportunity and Challenge for IS Research," Information Systems Research, (25:3), 2014, pp. 443-48.

[2] M. Alavi and D.E. Leidner, "Review: Knowledge Management and Knowledge Management Systems: Conceptual Foundations and Research Issues," MIS Quarterly, (25:1), 2001, pp. 107-36.

[3] E. Anzilotti, "How Mastercard's "Data Philanthropy" Program Is Tackling The Global Financial Information Gap,” 2017, Retrieved May 30, 2018, from

https://www.fastcompany.com/40457902/how-mastercardsdata-philanthropy-program-is-tackling-the-global-financialinformation-gap.

[4] K.W. Artz and T.H. Brush, “Asset Specificity, Uncertainty and Relational Norms: An Examination of Coordination Costs in Collaborative Strategic Alliances," Journal of Economic Behavior \& Organization, (41:4), 2000, pp. 337-62.

[5] J. Barney, "Firm Resources and Sustained Competitive Advantage," Journal of Management, (17:1), 1991, p. 99.

[6] S. Brammer and A. Millington, "Does it pay to be different? An analysis of the relationship between corporate social and financial performance," Strategic Management Journal, (29:12), 2008, pp. 1325-43.

[7] H. Chen, R.H. Chiang and V.C. Storey "Business intelligence and analytics: From big data to big impact," MIS Quarterly, (36:4), 2012, pp. 1165-1188.

[8] R.H.L. Chiang, V. Grover, T.P. Liang and D.Z.G. Editors, "Special Issue: Strategic Value of Big Data and Business Analytics. Journal of Management Information Systems," (35:2), 2018, pp. 383-387.

[9] T.R. Crook, D.J. Ketchen, J.G. Combs and S.Y. Todd, "Strategic Resources and Performance: A Meta-Analysis," Strategic Management Journal, (29:11), 2008, pp. 1141-54. [10] T. R. Crook, J.G. Combs, D. Ketchen and H. Aguinis, "Organizing around transaction costs: What have we learned and where do we go from here?," Academy of Management Perspectives, (27:1), 2013, pp. 63-79.

[11] T.H. Davenport and D.J. Patil, "Data Scientist: The Sexiest Job of the 21st Century," Harvard Business Review, 2012.

[12] A. Dudezert and D.E. Leidner, "Illusions of Control and Social Domination Strategies in Knowledge Mapping System Use," European Journal of Information Systems, (20:5), 2011, pp. 574-88.

[13] European Commission, "Enter the Data Economy: EU Policies for a Thriving Data Ecosystem," EPSC Strategic Notes, (21), 2017, 16.

[14] M. Friedman, "The social responsibility of business is to increase its profits," in Corporate Ethics and Corporate 
Governance, Springer Berlin Heidelberg, pp. 173-178, 2007.

[15] P.C. Godfrey, C.B. Merrill and J.M. Hansen, "The relationship between corporate social responsibility and shareholder value: an empirical test of the risk management hypothesis," Strategic Management Journal, (30:4), 2009, pp. $425-45$.

[16] J.R. Gil-Garcia and T.A. Pardo, "Multi-Method Approaches to Digital Government Research: Value Lessons and Implementation Challenges," Proceedings of the 39th Hawaii International Conference on System Sciences, 2006.

[17] "Google Trends - Top Charts," 2017, (available at https://trends.google.com/trends/topcharts; retrieved March 28, 2017).

[18] K. Graber, "Mastercard Joins with Unilever to Empower Small Merchants | Payment Facilitator," 2017, Retrieved May 31, 2018 from https://www.paymentfacilitator.com/business/mastercardjoins-with-unilever-to-empower-small-merchants/. [19] R.M. Grant, "Toward a Knowledge-Based Theory of the Firm," Strategic Management Journal, Chichester, 17(Winter Special Issue), 1996, 109.

[20] B.T. Hazen, C.A. Boone, J.D. Ezell and L.A. JonesFarmer, "Data quality for data science, predictive analytics, and big data in supply chain management: An introduction to the problem and suggestions for research and applications," International Journal of Production Economics, (15:4), 2014, pp. 72-80.

[21] R.E. Hoskisson, W.P. Wan, D. Yiu and M.A. Hitt,

"Theory and research in strategic management: swings of a pendulum,". Journal of Management, (25:3), 1999, pp. 417-456.

[22] S. Hurst, "Mastercard Teams Up With Unilever to Launch Digital Lending Platform For Kenyan Entrepreneurs," 2018, Retrieved May 31, 2018, from https://www.crowdfundinsider.com/2018/05/132830mastercard-teams-up-with-unilever-to-launch-digitallending-platform-for-kenyan-entrepreneurs/.

[23] J. Kraaijenbrink, J.C. Spender and A.J. Groen, "The

Resource-Based View: A Review and Assessment of Its

Critiques,". Journal of Management, (36:1), 2010, pp. 349372.

[24] R. Kirkpatrick, “A New Type of Philanthropy: Donating Data,” Harvard Business Review, March 21. 2013.

[25] N. Malhotra and J. Dann, "Business Ethics Integral to Corporate Strategy," cbsnews.com. Retrieved Aug 26, 2018.

[26] K.E. Martin, "Ethical issues in the Big Data industry," MIS Quarterly Executive, (14:2), 2015, p. 2.

[27] O. Müller, M. Fay, and J. vom Brocke, "The Effect of Big Data and Analytics on Firm Performance: An

Econometric Analysis Considering Industry

Characteristics," Journal of Management Information

Systems, (35:2), 2018, pp.488-509.

[28] M. Orlitzky, F.L. Schmidt and S.L. Rynes, "Corporate social and financial performance: A meta-analysis," Organization Studies, (24:3), 2003, pp. 403-41.

[29] A. Pawelke and A.R. Tatevossian, "Data Philanthropy: Where Are We Now?| United Nations Global Pulse,"
2013. Retrieved February 28, 2018, from https://www.unglobalpulse.org/data-philanthropy-whereare-we-now.

[30] P. Ponniah, "Data Warehousing Fundamentals: A Comprehensive Guide for IT Professionals," John Wiley \& Sons, 2004.

[31] B. Seifert, S.A. Morris and B.R. Bartkus, "Having, Giving, and Getting: Slack Resources, Corporate Philanthropy, and Firm Financial Performance," Business \& Society, (43:2), 2004, pp. 135-61.

[32] S. Singh, "A Call to Action on Data Philanthropy," 2016. Retrieved June 12, 2018, from

https://www.linkedin.com/pulse/call-action-dataphilanthropy-shamina-singh/.

[33] M. Stempeck, "Sharing Data Is a Form of Corporate Philanthropy," Harvard Business Review, July 24, 2014.

[34] M. Taddeo, "Data philanthropy and the design of the infraethics for information societies," Phil. Trans. R. Soc. A, 14 November, 2016

[35] TechMoran. "Mastercard \& Unilever launch "Jaza Duka," inventory-backed loans to empower micro entrepreneurs in Africa,". 2018, Retrieved May 31 from https://techmoran.com/mastercard-unilever-launch-jazaduka-inventory-backed-loans-to-empower-microentrepreneurs-in-africa/.

[36] D.J. Teece, "Profiting from technological innovation: Implications for integration, collaboration, licensing and public policy," Research Policy, (15:6), 1986, pp. 285-305. [37] D.J. Teece, G. Pisano and A. Shuen, "Dynamic capabilities and strategic management," Strategic Management Journal, 1997, pp. 509-33.

[38] T.S.H. Teo, R. Nishant and P.B.L. Koh, "Do shareholders favor business analytics announcements?," Journal of Strategic Information Systems, (25:4), 2016, pp. 259-276.

[39] United Nations Global Pulse, "Big Data for Development: A primer," UN Global Pulse, 2013, p. 8 (available at http://unglobalpulse.org/bigdataprimer). [40] UPS. "Using data as a force for good," 2016, Retrieved May 30, 2018, from

https://solvers.ups.com/what-if-2016/using-data-as-a-forcefor-good-ted-ups-video/.

[41] H. Wang, J. Choi and J. Li, “Too Little or Too Much? Untangling the Relationship Between Corporate Philanthropy and Firm Financial Performance," Organization Science, (19:1), 2008, pp. 143-159. [42] H. Wang and C. Qian, "Corporate Philanthropy and Corporate Financial Performance: The Roles of Stakeholder Response and Political Access," Academy of Management Journal, (54:6), 2011, pp. 1159-81.

[43] S. Wunder-Smith, "CHHS Alumna Mallory Soldner now "Doing Good with Data" at UPS!" 2016, Retrieved May 31, 2018, from http://hg.gatech.edu/node/585133. 